This is a self-archived - parallel published version of this article in the publication archive of the University of Vaasa. It might differ from the original.

\title{
Drawing conclusions about what co-participants know : knowledge-probing question-answer sequences in new employee orientation lectures
}

Author(s): Mikkola, Piia; Lehtinen, Esa

Title: Drawing conclusions about what co-participants know : knowledge-probing question-answer sequences in new employee orientation lectures

Year: $\quad 2019$

Version: Accepted manuscript

Copyright (C)2019 the author(s), licensee SAGE Publications. The article is protected by copyright and reuse is restricted to noncommercial and no derivative uses. Users may also download and save a local copy of an article accessed in an institutional repository for the user's personal reference.

\section{Please cite the original version:}

Mikkola, P., \& Lehtinen, E. (2019). Drawing conclusions about what co-participants know : knowledge-probing questionanswer sequences in new employee orientation lectures. Discourse and Communication 13(5), 516-538. https://doi.org/10.1177/1750481319847361 
Drawing conclusions about what co-participants know: Knowledge-probing question-answer sequences in new employee orientation lectures

Short title: Drawing conclusions about what co-participants know

Corresponding author:

Piia Mikkola

The School of Marketing and Communication

University of Vaasa

Second author:

Esa Lehtinen

Department of Language and Communication Studies

University of Jyväskylä 


\begin{abstract}
This study aims to uncover the processes of interaction through which knowledge acquisition in new employee orientation is monitored and controlled. Using video-recordings of orientation lectures as data, the study focuses on question-answer sequences in which the lecturer's question probes into the state of the employees' knowledge; in particular, it looks at the third turn of the sequence, in which the lecturer comes to a conclusion concerning the participants' knowledge. This is shown to be an unavoidably practical accomplishment, which is contingent on both the often ambivalent responses of the participants and the design of the knowledge-probing question. Also, the lecturer orients to being responsible for providing the employees with the necessary knowledge that they do not have. The study contributes to discussion of the interactional organization of knowledge in institutional settings, and it sheds light on the pros and cons of lectures as interactional encounters.
\end{abstract}

Keywords: new employee orientation, lecture, question-answer sequence, knowledge probing question, conversation analysis, multimodality

\title{
Autobiographical notes
}

Piia Mikkola is a post-doctoral researcher at the University of Vaasa, Finland. In her dissertation she has investigated, from the interactional perspective, the role of the written interview form in performance appraisal interviews. As a post-doctoral researcher she has continued studying interaction in organizational contexts. Recently, she has focused on knowledge delivery in group-based new employee orientation.

Esa Lehtinen is Professor of Modern Finnish at the University of Jyväskylä, Finland. He has conducted research on discourse in organizational, medical and religious contexts. Recently, he has been particularly interested in how face-to-face encounters and written documents are intertwined in organizational discourse. He has published his work, for example, in Journal of Pragmatics, Language and Communication, Pragmatics, and Scandinavian Journal of Management. 


\section{Introduction ${ }^{1}$}

Working life in the $21^{\text {st }}$ century requires a growing amount of specialized expertise. The foundation of this expertise is generally acquired in occupational and higher education programs, which might involve training or apprenticeship in work environments (for studies on language and interaction in vocational training and apprenticeship contexts see Goodwin 1994; Hindmarsh, Reynolds \& Dunne 2011; Koskela \& Arminen 2012). However, when an employee begins in a new position, he or she also needs to acquire the knowledge presupposed in that specific organization. Organizations' orientation programs, which can involve both vocational training and group-based orientation lectures (Stephens \& Dailey 2012: 405), are important tools for socializing new employees into their positions. Especially the orientation lectures - which are in focus in this study - have remained unexplored from the interactional viewpoint.

Some studies have approached new employee orientation by means of theoretical models and questionnaires. These studies have pointed out that orientation is a critical phase for both the new employee and the organization: orientation can affect work performance, motivation and satisfaction (Griffin, Colella \& Goparaju 2000: 463, 470; Klein \& Weaver 2000: 60; Wallace 2009: 169, 171). However, since previous studies have not approached orientation lectures from the perspective of interaction, there is a need to understand how these lectures are conducted in real-life contexts. In this study we will answer this need by analyzing new employee orientation lectures with the help of video-recorded data.

A central aim of the orientation period is to give new employees enough knowledge and skills to be able to start working in their new position. From this perspective, groupbased orientation has both advantages and disadvantages. It is a convenient way to deliver information to a large number of people simultaneously. However, the challenge of group-based orientation is the difficulty of following the learning process of individual members of the group. In this paper we will focus on the very moments in group-based orientation when the state of the group's knowledge is explicitly discussed.

We concentrate on question-answer sequences that include what we call knowledgeprobing (see Artemeva \& Fox 2010) questions put by the lecturer. These questions probe what and how much the employees have grasped in terms of work-related matters and skills. The sequences consist of three parts: the lecturer's question, the employees' responses, and the lecturer's third turn, in which he or she displays her or his conclusion as to what the employees know and whether it is sufficient for the time being.

In particular, we concentrate on the third turn. Our aim is to find out how the lecturers reach conclusions about the participants' stock of knowledge (Artemeva \& Fox 2010: 502) and how the orientation lecture is continued in consequence of this conclusion. We show that the third turn is contingent on both the design of the knowledge-probing question and the responses produced by the new employees. We also show how

\footnotetext{
${ }^{1}$ This work was supported by the Finnish Work Environment Fund.
} 
challenging the lecturer's twofold task is: if the new employees turn out not to possess the required information, the lecturer is responsible for delivering this information to the audience (cf. Hindmarsh et al. 2011: 501). However, as we will demonstrate, in most cases he/she cannot find out reliably what all the new employees in the group know or do not know. Thus, the conclusion the lecturer reaches in the third turn is unavoidably practical.

\section{Institutional encounters as environments for sharing knowledge and expertise}

As there are virtually no earlier interactional studies of group-based orientation lectures, in this section we will describe them by comparing them with other kinds of encounters where knowledge and expertise are shared.

From the perspective of participant roles, orientation lectures resemble training and apprenticeship. Previous studies have mostly focused on the medical field (Hindmarsh et al. 2011; Mondada 2003). There are also studies on training in archaeology (Goodwin 1994), air traffic control (Koskela \& Arminen 2012) and piloting (Melander \& Sahlström 2009). All of these contexts are similar to orientation lectures in that the senior participants in the organization adopt a supervisory role: they introduce the work tasks to newcomers and give advice.

A central difference between training and new employee orientation lectures is, however, the fact that during orientation lectures the participants are not involved with authentic work tasks. The knowledge that is transmitted and discussed during orientation lectures is very generalized in comparison with the practical, task-specific knowledge of the training sessions (see Svensson et al. 2009: 892). Another difference between new employee orientation and vocational training is the number of participants involved in the encounters. Training generally involves only two participants (see for example Goodwin 1994; Hindmarsh et al. 2011), whereas orientation lectures are multiparty settings. From this perspective, orientation resembles classroom interaction (see for example Margutti 2006; Mehan 1979), which has the similar pedagogical objective of sharing knowledge.

In classroom interaction as well as in orientation lectures the participants process, learn and discuss new information together in a group. Both types of encounter are led by one person, a teacher or lecturer. New employee orientation lectures also contain sequences typical of classroom interaction, such as the three-part IRE-sequence ${ }^{2}$ (see Mehan 1979: 49-65). Still, there are differences between orientation lectures and classroom interaction: during orientation, new employees are expected to become competent members of a professional community - an outcome that is not expected of students.

For the lecturer, as for a teacher, one major challenge is to ensure that his or her instructional activities fit in with what the learners already know, in a situation where

\footnotetext{
${ }^{2}$ Initiation - response - evaluation.
} 
levels of knowledge may be variable. In our study, we will investigate the lecturer's practical ways of coming to terms with the challenges specific to orientation lectures.

\section{On the epistemics of (knowledge-probing) question-answer sequences}

Our study also contributes to the study of question-answer sequences in institutional encounters, in particular from the standpoint of orientation to knowledge and expertise. In this respect, we will use the notion of epistemics (Heritage 2012a). In the following, we will set the knowledge-probing question-answer sequence in the context of other related types of question-answer sequences in order to shed light on the kind of contribution we can make to this discussion. Our main focus in this article is on the third turn of the sequence, but in order to understand the third turn, we need an understanding of the questions and answers as well.

The knowledge-probing questions in our data are asking for information about what the employees already know and/or have learned about some specific work-related topic, concept or task. They are usually formulated linguistically as polar interrogatives: e.g. onks teille näytetty se meijän se vastaustukijuttu jo 'have they already shown you that our that answer support thing'. ${ }^{3}$ The respondents are expected to confirm or deny their knowledge, which will be based on their personal experience. Although the concept of knowledge-probing question (on the concept of knowledge probing, see Artemeva \& Fox, 2010) has not been used before, similar question-answer sequences have been analyzed earlier in ordinary conversation (Svennevig, 2010), in a pedagogical context (Kim, in press), and in workplace interaction (Nissi \& Lehtinen, 2016). In all these contexts, such questions are used to check whether and what the participants already know about a specific concept and issue, and as a preamble to informing the coparticipant about the issue.

The linguistic concept of epistemics has been used in conversation analysis to refer to people's orientation in interaction to knowledge (Heritage, 2012a; 2012b; Stivers, Mondada \& Steensig, 2011). Heritage (2012a) makes a distinction between epistemic status and stance. By status he means a person's relatively stable rights and obligations with regard to a certain territory or domain of knowledge. For example, we are all treated as knowledgeable vis-á-vis our personal experiences, while professionals are treated as experts in their respective professional domains; e.g. doctors are treated as knowledgeable in terms of medical knowledge. With epistemic stance, on the other hand, Heritage means the situated expression of a knowledge state in interaction.

As Heritage (2012a, b) shows, questions are an action in which epistemics plays an important role. Earlier research in training contexts shows that they often include so-

\footnotetext{
${ }^{3}$ Two of the question are wh-questions: mitä teil on siitä niinku puhuttu 'what have they told you about it'. One turn is formulated as a declarative but it works as a question (see Extract 1 ).
} 
called test questions (e.g. Koskela \& Arminen, 2012). Test questions are an important part of pedagogical interaction (see e.g. Mehan, 1978), as part of the initiative-replyevaluation sequence. As far as epistemics is concerned, test questions differ fundamentally from 'real' questions that work as genuine requests for information. In test questions, the teacher or instructor asks the question and evaluates the answer from a knowledgeable position, while in information requests it is the answerer who is treated as more knowledgeable. This has to do with the epistemic status of the teacher or the instructor with regard to the professional domain with which the instruction is concerned.

However, there is variation in the epistemic stance of both test questions and information requests. For example, as Margutti (2006) shows, teachers may display their expectation of whether or not the students know the answers to their test questions. Raymond (2010), on the other hand, with regard to information requests made by health visitors, shows that the questioners may signal in their question whether they know something about the expected answer or not.

Knowledge-probing questions are unequivocally true information requests. That is, the information they ask for concerns the personal experience of the employees, a domain of knowledge in which they are treated as knowledgeable. However, at the same time, the lecturer is treated as more knowledgeable about the topic of the question, that is, the work-related concept or task he or she is asking about. Thus, this is not a request to be informed about the topic itself, only a question about the employees' knowledge and experience of the topic. This is important with respect to the sequence as a whole, and in particular the third turn. In the third turn the lecturer evaluates not the correctness of the answer, as in test questions, but the sufficiency of the employees' knowledge of the topic. This evaluative activity is only possible for someone who knows more about the topic itself.

It is also worth noting that there are differences in the preference structure of questions. As Harvey Sacks (1987) observed, polar questions usually display a preference toward either a 'yes-type' or a 'no-type' answer. In our data, the questions mostly prefer 'yestype' answers, but there are more subtle differences in the preference structures that seem to be connected to the topic of the question. When the question concerns knowledge or skills the employees are presumed to have acquired during the orientation period, the questions usually prefer the affirmative answer quite strongly. However, when the questions deal with knowledge that the employees could have obtained before the orientation period, the preference for an affirmative answer is much weaker: in these cases, the form of the question implies an expectation that only some of the employees will be able to answer affirmatively. In other words, the lecturers, in their questions, display their expectation of how knowledgeable the employees will be with regard to the topic of the question. In conclusion, in the sequences that are examined in this study, there is a complex set of epistemic orientations at play that have to do with both the 
participants' rights and obligations to know about their own experience, and their rights and obligations with regard to domains of professional knowledge.

\section{Data and method}

The data consist of orientation lectures from an orientation program in a Finnish public organization. The orientation program involves presenters from the organization and a group of 30 new employees who are going to work in a customer service unit. The program lasts seven weeks altogether, and we have video-recorded the lessons on three orientation days. All in all, we have 11 hours and 20 minutes of data.

The data were recorded with two video-cameras, one of which mostly filmed the front side of the lecture room (see Figure 1), while the other one was placed so that it filmed the audience (see Figure 2). Figures 1 and 2 illustrate the same moment, taken from different cameras.

\section{FIGURES 1 AND 2 HERE}

In the data there are altogether six lecturers who, at different times, present the materials to the audience. A distinctive feature of the data is that there can be long monologues by the lecturer, during which there is little interaction between the lecturer and the new employees. However, there are also more interactional phases during the lectures. Four of the lecturers present knowledge-probing questions in the data, thus interacting with the new employees.

We went through the research data and found 15 instances or sequences that include the following turns: (1) a knowledge-probing question by the lecturer, (2) responses by the new employees and (3) a third turn, in which the lecturer draws some kind of a conclusion about the situation. There were 21 questions that probe knowledge in these 15 instances, since in some cases the lecturer produced more than just one question. As a methodology we applied multimodal conversation analysis (cf. Goodwin 2000; Streeck, Goodwin \& LeBaron 2011). For our analysis, this means that we attended to the sequential structure of the interaction, taking into account linguistic as well as embodied resources for social action, such as gestures, facial expressions and postures.

\section{Analysis}

The principle focus of attention in the analysis is directed towards the third turn produced by the lecturer, in which the lecturer displays his/her conclusion about what the employees know. Consequently, we divide our analysis into cases where he or she deems their knowledge to be sufficient (5.1) and cases where the orientation is to insufficient knowledge (5.2). We also look at how the lecturer goes on with the activity on the basis of that conclusion, and how the conclusion is contingent on the question in the first turn and the employees' responses. Finally, we present an exceptional case (5.3), in which the direction of the encounter changes after the third turn because of a 
new contribution by an employee. Thus, the analysis also uncovers the challenges the lecturerfaces in finding out whether new employees already know something or not.

\subsection{Orienting to employees' having sufficient knowledge}

In this section, we analyze two extracts that exemplify instances where the lecturer in the third turn displays an orientation to the employees' possessing the knowledge in question - at least adequately. Both of the questions have to do with knowledge the participants could have acquired during the orientation phase.

Extract 1 shows a fairly simple, typical case. Before the beginning of the extract the lecturer has instructed the new employees that they should direct a group of customers, entrepreneurs, to use an online service. The extract starts as the lecturer suggests that they could illustrate the possibility of using the online service with the help of a demonstration. The knowledge-probing question follows in lines 4, 5 and 7, and it is connected with the earlier remark concerning the demonstration.

\section{Extract 1}

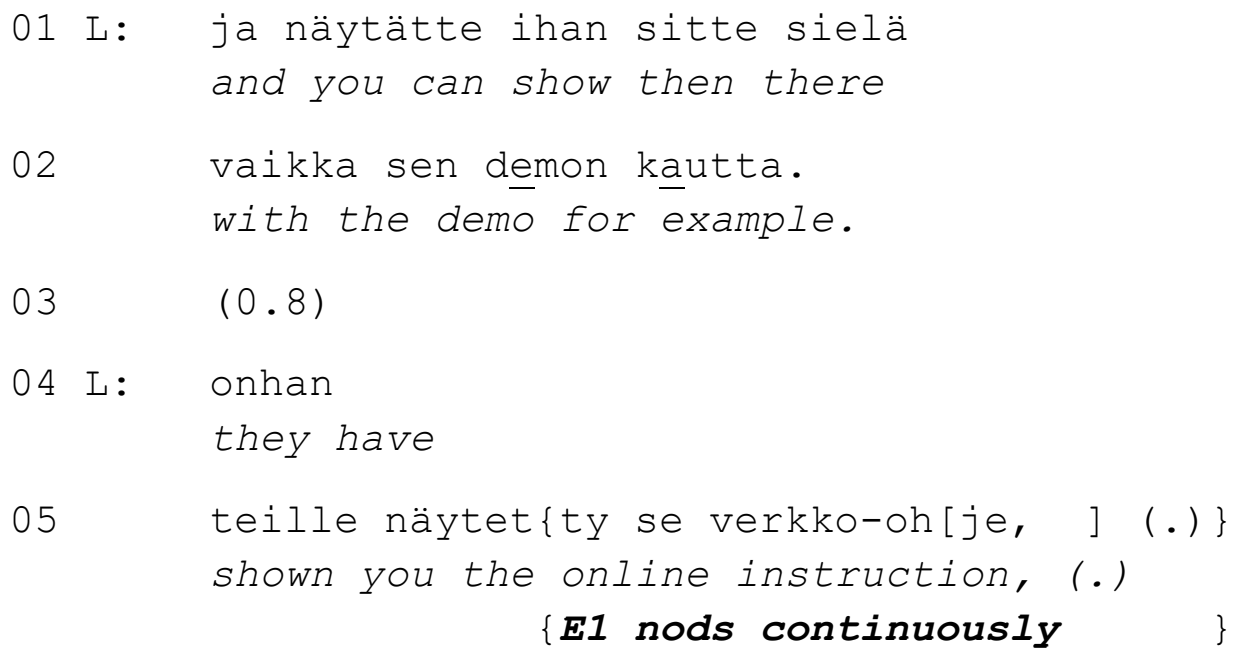

$07 \mathrm{~L}: \quad[\{$-demo. $\}$

demo haven't they.

E1 nods $\}$

08 P2: $[\{\mathrm{m}[\mathrm{m}$,
$\{E 2$ nods once
\{E3 purses her lips

09 E4: [mm,

10 L:-> joo. (.) se on hyvä .hh ni sen kans pystyy sitte 
yeah. (.) it's good.hh so with it one can then

11

näyttää et mihin se yrittäjäkin laittaa sinne show where even the entrepreneur can set

12

niitä, (.) ${ }^{\circ}$ juttuja ${ }^{\circ}$

those, (.) ${ }^{\circ}$ things ${ }^{\circ}$

13

$(0.8)$

14 L: MUISTUTA YRITYKSEN TULOKSEN

REMIND THEM THAT THE RETURNS OF THE ENTERPRISE

15

SEURAAMISESTA ENNAKOIDEN ajalla-

MUST BE FOLLOWED to keep the advances up-

16

ajan tasalla pitämiseksi?

up-to-date

To be able to understand the design of the third turn, we first need to pay attention to the previous turns: the knowledge-probing question and its responses. The knowledgeprobing question in Extract 1 is designed as a declarative with the clitic particle -han (onhan teille näytetty, line 4). Such declaratives work in Finnish as questions that ask for confirmation (see, VISK, §830). The clitic particle implies that the questioner already knows the expected answer, and the question prefers an affirmative answer.

Such a preference is typical of questions that deal with knowledge the participants should have acquired during the orientation phase. Questions of this kind suggest that the new employees are held accountable for learning, knowing or at least being aware of some information. They also typically treat the audience as one uniform group that shares the same knowledge. The questions are directed to respondents by using the pronoun te '(plural) you' (line 5) or the particle kaikki 'everyone' (see Extract 2).

Responses to knowledge-probing questions can be both verbal and embodied, and they are usually quite minimal. Embodied reactions in the data are, for example, nodding, shaking one's head or raising a hand. Response particles such as $m m$ and joo ('yes') are also typical. In Extract 1, the first reaction comes in early during the question: E1 starts nodding at line 5 during the word näytetty 'shown'. Then she produces an agreeing particle $m m-m$ while she keeps on nodding. Two other new employees also join in: E2 and E4 produce the response particle $\mathrm{mm}$ and E2 nods once. Thus, these three employees indicate that they know the demonstration in question.

There is, however, one employee (E3) whose facial expression at line 8 hints the opposite: she purses her lips. This facial expression can be interpreted as an indication of E3 lacking the information the lecturer is enquiring about. This means that even 
though the lecturer in this extract treats her audience as one uniform group, there is evidence that this might be unjustified.

Let us now move to the central feature of our analysis and look at the design of the third turn, by the lecturer. Generally, there are two ways of formulating third turns in the data. Most of them (9 cases) are formulated as conclusions that explicitly affirm the audience's being in possession of the required knowledge, e.g., et se on nyt teille tuttu 'so you are now familiar with it'. The other category (6 cases) consists of turns that are designed as positive evaluations (hyvä 'good'), acknowledgement tokens (joo nii just joo 'yeah right yeah') or a combination of the two.

The third turn in Extract 1 (lines 10-12) belongs to the latter category: at the beginning of the turn the lecturer produces the particle joo ('yeah', line 10). Then she goes on to present an assessment of the demonstration (lines 10-12). A central feature from the point of view of our analysis is what follows: after a pause at line 13, the lecturer initiates a new topic with regard to the instruction she was going through earlier. In this way the lecturer treats the situation as unproblematic - the audience possesses the knowledge she has referred to in her enquiry - and she moves on. There is, for example, no need to explicate where the demonstration is to be found. If the facial expression of E3 indicates that she lacks the information, this delicate cue passes unnoticed.

A significant feature of question-answer sequences in group-based orientation is the fact that not all of the participants in the audience react to the lecturer's knowledge-probing questions. There are usually only a few participants who actually do react - in this case four. This naturally creates a challenge for the lecturer with respect to coming to a conclusion about how much the audience know. What is interesting is that the lecturer does not seem to look for a logically conclusive solution to this problem: he/she does not wait to get a reaction from all the participants. Instead, the lecturer draws a conclusion using the reactions he/she can perceive, in relation to the expectations displayed in her question. This means that the lecturer looks for a solution that is good enough for all practical purposes. In the third turn in Extract 1, the lecturer orients to the group's knowing about the demonstration. This is a state of affairs that three new employees (E1, E2, E4) in the audience have indicated and the lecturer herself has anticipated in her question.

The second extract resembles the first one in that both cases exemplify a knowledgeprobing polar question that clearly prefers an affirmative answer. However, the situation in Extract 2 turns out to be more complicated because it becomes clear that there are a lot of participants who do not possess the knowledge the lecturer is asking about. What is significant, though, is that the lecturer concludes in the end that the new employees are sufficiently knowledgeable. This conclusion makes it possible for her, just like in Extract 1, to move on to the next topical item. 
01 L: tota: saiko- pääsikö kaikki tekemään

er:m could- did everyone get to practice

02

henkilötun\{nust $\{a$, (.) >tai\} onko\} joku joka<

the identity number, (.) >or is there anyone<

$\{\mathrm{E} 1 \mathrm{nods}$

$\{$ E2 nods

$03\{>e[i$ päässy $<$,

$>$ who didn't<,

$\{L$ moves her head from side to side

04 E3: [se oli

it was

05 E3: \{just vähä huono se \{Myllylä per\}jantaina\} koska:\}

a little bit tricky that Myllylä on Friday becau:se

$\{\mathrm{E} 4$ puts up her hand
$\{\mathrm{E} 5$ puts up her hand
$\{\mathrm{E} 6$ puts up her hand

06 E3: siellä ei ollu asiakkaita et niin ne sano

there were no customers so they said

\section{((4 lines omitted))}

11 E2: sainkoha mä

I think I got to

12 kaks tehä siinä omutta ${ }^{\circ}$

do it ((the identity number)) twice there 'but ${ }^{\circ}$,

13 L:-> mut kuitenki fet on suurin osa on kuitenki päässy

but anyhow most of you have got to

\section{$\{\mathrm{E} 2$ nods once}

$14\{$ tekemään sen, (.) että\} elikkä oikeudet näköjää practice it, (.) so the credentials appeared to be $\{E 7$ nods

15 £toimi£ kum mä miet[in, (.) $£ k(h) y l$ th) oimi£ £working£ as I thought (.) ft(h)hey w(h) ere

$16 \mathrm{E} 2:$

$$
\begin{aligned}
& {[£ j \circ(h) \circ £} \\
& \text { yeah }
\end{aligned}
$$

17 L: sitte ja tämmöstä näi ja ja: milt se w(h)orkinge then and like that and a:nd how did it 
Before the beginning of Extract 2 the lecturer has asked the new employees to share their experiences of the training day on the previous Friday. In line 01 the lecturer presents a knowledge-probing question. The question is related to a certain kind of training experience, one to do with customers' identity numbers. The question is similar to the one in Extract 1 in that it relates to knowledge the participants could have acquired during the orientation period and it prefers an affirmative answer. The pronoun kaikki ('everyone') conveys the meaning that every member in the group is expected to have undergone the same training experience.

One relevant aspect of this knowledge-probing question is the nature of the knowledge involved. It relates to experience that can only be acquired during training days. Thus, the lecturer simply could not deliver the knowledge or experience about the identity number training to the audience even if she wanted to.

Let us take a look at the responses. Two members of the audience (E1, E2) nod at line 02 as the lecturer pronounces the word henkilötunnus 'identity number'. The majority of the audience, however, remain still and silent. After a micropause, the lecturer formulates her question differently (lines 02, 03): 'or is there anyone who didn't'. This design of the question projects a different answer than the first one. Now those participants who lack the training experience are expected to respond. This way the lecturer lowers her expectations of the state of the group's knowledge: there might be some participants who have not had the experience. It is important to note, however, that both questions still share the same expectation that a majority of the new employees have had the training experience.

The second formulation of the knowledge-probing question leads to different kinds of responses: four new employees indicate that they do not have the training experience. E3 initiates her verbal answer already in line 04 . Soon after that, three other new employees (E4, E5, E6) react by raising their hands. In her verbal answer (lines 04-06), E3 produces an account of why she could not practice that aspect of the training: there were no customers in the office. As has already been mentioned, minimal responses are common reactions to knowledge-probing questions. Longer verbal explanations, however, tend to occur when the lecturer's question clearly prefers an affirmative answer but participants do not possess the expected knowledge. In such instances, the participants' verbal explanations account for their lack of knowledge.

E3 treats the lecturer's questions as not purely information-seeking but also evaluative (cf. Raymond 2010: 98, 99). The questions not only look for information, but at the same time they explicate the expected state of affairs. When producing a verbal explanation, E3 deals with this evaluative aspect while simultaneously answering the question itself. In line 11, E2 joins in and explains that she could only practice the identity number twice. At this point it is clear that only some of the participants have been able to gain any experience with the identity number. What is significant is that in 
the third turn (lines 13,14) the lecturer, in spite of the varying responses, concludes that the employees are sufficiently knowledgeable: 'but anyhow most of you have got to practice it'. Since the lecturer has now reached a conclusion that treats the situation as unproblematic, she is able to move on to the next topic (lines 14,15). Thereafter she presents another question that, interestingly, builds on the assumption that the group has the experience she has been asking about (lines 17, 18).

To sum up: Through knowledge-probing question-answer sequences, the participants negotiate whether new employees possess sufficient knowledge. Nevertheless, it is the lecturer who has the right, and the responsibility, to draw the final conclusion and proceed accordingly. In this section, we have analyzed cases where the lecturer orients to new employees' having sufficient knowledge. In coming to a conclusion, the lecturer draws on various resources. He/she relies in the first place on the new employees' responses, but they are clearly not totally conclusive. Even though the new employees might produce contradictory responses, as in Extract 2, the lecturer can still draw a positive conclusion as to the adequacy of the participants' knowledge. This can happen if he or she can perceive at least some affirmative responses in the audience, if the positive answer is what he or she has projected in the question, and if the issue is such that he/she cannot deliver the relevant information to the employees. This shows that the conclusion in the third turn is based not only on the new employees' responses but also on the kind of question and kind of issue in question. In most cases, however, the lecturer is able and ready to deliver the missing information to her or his audience. This will be demonstrated in the following extracts, where the lecturer orients to insufficient knowledge on the part of the new employees.

\subsection{Orienting to employees' having insufficient knowledge}

In this section, we will analyze cases where the lecturer concludes that the employees do not possess enough of the relevant knowledge. Extract 3 is quite a similar case to the ones in the previous section. The lecturer's conclusion is based, for the most part, on the responses.

\section{Extract 3}

( lecturer is standing in front of the class, employees are sitting at tables with computers))

\{onks teille kerrottu siit meiän

have you been told about our

points at slide with finger 
03

$$
\{(1.5)
$$

E1 shakes head

04 L: \{ootteko ikinä kuullu, (.)

have you ever heard, (.)

\{E1 shakes head

05 Organisation X

of the standardization instructions

06 \{yhtenäistämisohjeesta?

of Organization $X$ ?

$\{\mathrm{E} 1$ shakes head

$07 \quad(0.7)$

08 E?: $\{\mathrm{mm}$

\{E2 raises hand

09 E?: $\{\mathrm{mm}$

\{E2 with hand up

10 E?: $\{\mathrm{mm}-[\mathrm{m}$ ?
\{E1 shakes head
$\{\mathrm{E} 2$ lowers hand

$11 \mathrm{~L}:->\quad[$ s $\underline{\text { ä }}$ oot kuullu?

you have heard?

12 (.)

\{points finger at E2

13 E2: ${ }^{\circ}$ joo. ㅇ

oyeah.。

14 L: joo.

yeah.

$15 \quad($.

16 E2: mä jouduin tarkistaa sielt (jotain).

I had to check (something) there.

((2 lines omitted)) 
$\begin{aligned} & 19 \mathrm{~L}: \quad \text { okei. (.) joo (.) siel on hyvin kerrottu tää } \\ & \text { okây. (.) yeah (.) it's well explained there this }\end{aligned}$ \{lowers hands

(.) \{ää-krhm kohta että (0.2) millon (.) mikäkin fer krhm item (0.2) when (.) this and that \{looks at slide (.) Voi kuulua sinne elinkeino\{toiminnan (.) can belong to the business

\{looks at computer

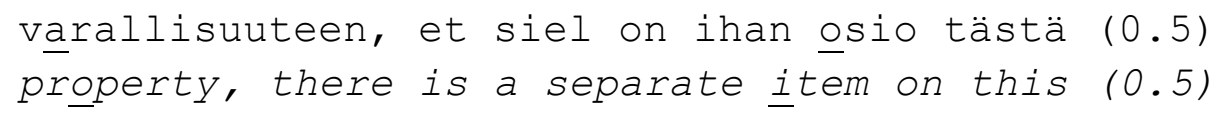

Before the beginning of the extract, the lecturer has been giving the new employees information. She interrupts this in order to ask a question, in lines 1-2. The question involves an issue the employees could have learned during their orientation period. It prefers a positive answer. After the question, many of the employees look at the lecturer but they do not produce responses. One of the employees shakes her head slightly. At this point, there is no evidence of a positive response from any of the employees.

While, as we saw in the previous section, lecturers often accept a few positive responses as a sufficient display of knowledge, getting no positive responses (or, in some cases, just one response) is treated as problematic. However, the lecturer does not yet draw a final conclusion as to whether or not the employees know about this. Rather, she rephrases the question (lines 4-6). The new form of the question is different from the first one in that, instead of addressing what the employees have been 'told', it hinges on what they have 'heard'. In addition, she uses the adverb ikinä 'ever'. This modification distances the issue from the orientation program.

This time, the responses are different. There are three $m m$-tokens (lines 8-10) that may be interpreted as positive responses but remain equivocal. More importantly, one of the 
employees raises his hand (lines 8-9). This hand-raising the lecturer interprets as a positive answer (line 11), and the lecturer and the employee sort out together how specifically the employee has come into contact with the standardization instructions (lines 13-19, part of it not shown). Singling out one person in the group is important in the way that it constructs a situation where only one of the employees has knowledge of the issue.

In the third turn the lecturer first responds to E2 with acknowledgement tokens (line 19). Then she addresses the whole group and describes the document in question insofar as it concerns the issue she has been explaining before the question (lines 19-23). Then she asks the employees to remind her to show them the document later (lines 24-25). She thereby shows that she does not regard the employees as knowledgeable enough about the issue.

On the basis of Example 3 and other similar cases in the data, we can make two points. Firstly, we can see that the lecturer orients to the normative expectation that she is responsible for delivering the relevant information to the employees, either immediately or later, if they do not already know it. Secondly, we can refine our understanding of the lecturers' interpreting work of the resources available for drawing conclusions about the state of the employees' knowledge. As shown in the previous section, the lecture, as a multi-party encounter, is challenging in that respect. In the present case, just like in the previous extracts, most of the employees do not react to the question in any way. But, in this case, in response to the first question, none of them displays any knowledge, and one of them, through shaking her head, very clearly signals not knowing. There is therefore strong evidence of insufficient knowledge. As for the second question, one employee displays knowing about it, and three more respond ambiguously. This does not, however, constitute sufficient knowledge for the lecturer to move on to the next topic. In this respect, it is important to point out that the questions are different. The second question does not seem to call even for sufficient knowledge: just 'hearing of' an organizational document, in comparison to being 'told about' it, constitutes a fairly unspecified basis for organizationally relevant knowledge. We can see from this that the lecturer uses different kinds of questions to chart how much the employees know in order to decide how she should deal with the issue.

In the next extract we have a case in which the question concerns an issue that has not been discussed in the orientation program. As we will see, the lecturer concludes that the employees do not have sufficient knowledge on the matter. However, the interaction then proceeds differently.

\section{Extract 4}

01 L: onko kellekää mysteerisopping, (.) \{tuttu \{tai is mystery shopping familiar to, (.) any of you or 
\{ylipäätään toi palvelulaadun

evaluation of quality of services

\section{\{E2 nodding \\ \{E3 nodding \\ \{E4 raises hand}
03 -> >arviointi,=su- sulle on mysteerisoppaus
sin the first place=y- you are familiar with
$04\left\{\quad\right.$ o ${ }^{\circ}$ tuttua ${ }^{\circ}<$.
mystery ${ }^{\circ}$ shopping ${ }^{\circ}<$

\section{$\{E 4$ nods}

05

$(0.2)$

06 L: $\quad>$ m- mistä, <

$>f$ - from where, $<$

07

$(0.4)$

08 E4: A:lta,

from firm $A$

\section{( (3 lines omitted))}

12 E4: poistuin sieltä fabaut viis v(h) uott(h)a si[t(h)en£ I left the firm fabout five $y(h) \operatorname{ear}(h) s$ a[g(h)o£

$13 \mathrm{~L}:$

[okei

okay

14 no nii heh=joo. (.) mutta mä olin sillon olin all right heh=yeah. (.) but I was then working uhm

B:llä ${ }^{\circ}$ niin töissä tota $\left(\right.$ töissä) ${ }^{\circ}$ mut tota:, (0.3)

- (working) at firm $B^{\circ}$ but uhm, (0.3)

16 oo, hhh mysteerisopattiin meijän toimistoja, (.)

er, hhh our offices were mystery shopped, (.)

17 toista kertaa. (.) ja ja tota tavote oli 
In Extract 4, the lecturer is launching into a new topic. The topic is concerned with measuring the quality of customer service and, specifically, a method for doing it called 'mystery shopping'. The lecturer begins discussion of the topic with a question (lines 14) through which he probes into the employees' previous knowledge of the issue.

There are four employees who display knowledge of the issue. Three of them nod (lines $1-2$ ), and one of them raises her hand (line 2). As we have seen, the lecturer may interpret a few positive responses as sufficient demonstration of the employees' knowing about the issue. This time, however, he does not. Instead, he picks out one of the respondents, the one who has raised her hand, and explores further her knowledgeability (lines 3-4, 6). After the employee has explained how she got to know about 'mystery shopping' (lines 8,12 ), the lecturer produces acknowledgement tokens (lines 13-14), shares some aspects of his experience on the issue, and then goes on to explain the issue to the group (beginning in line 17).

It is important to note, however, that in this case, as well as in other cases where the question deals with knowledge possibly acquired elsewhere, the expectation of employees' not knowing is already indexed in the question. The question includes the pronoun kellekään 'any of you', thus displaying the expectation that only a few, if any, of the employees will be familiar with the issue. Consequently, the fact that there are four positive responses confirms the expectation of few knowledgeable employees, and it is not interpreted as sufficient knowledge.

All in all, we can conclude that the lecturer's third turn is contingent on both the employees' responses and the implication identifiable in the question. Drawing on these responses, he/she makes a practical decision as to whether or not he/she should deliver the relevant information to the employees.

\subsection{Changing orientation with regard to what employees know}

In this section, we will present an exceptional case, in which the orientation of the lecturer toward how much the employees know changes after the lecturer's initial concluding turn because of a new contribution made by an employee. This contribution makes it clear that the lecturer has misinterpreted what the employees know. This deviant case constitutes additional evidence for our claim about the dual position of the lecturer. In most cases the lecturer simply draws a practical conclusion about how much the group knows and proceeds accordingly. However, the lecturer also has an obligation to make sure that employees are sufficiently informed. In some cases, like in the case below, it becomes clear that the lecturer is in a position where she must deliver the missing information to the group. Extract 5, then, highlights the difficulty for the lecturer of interpreting what new employees do and do not know. 
Extract 5 begins at a topic juncture. The lecturer gets up from her chair and poses a polar question to the new employees (lines 1-5).

\section{Extract 5}

$01 \mathrm{~L}: \quad$ sit mä kysyn ennen kum mä unohdan et\} mä then I'll ask you before I forget so that I will \{gets up from the chair, looks at the slide\}

02 varmasti muistan sit näyttää ni certainly remember to show (it) then so

03 \{onks teille näytetty se have they shown you that \{looks at the audience

04 meijän se La- (.) Lavin ${ }^{\circ}$ vastaustukijuttu ${ }^{\circ}$ that our La- (.) Lavi's 'answer support thing ${ }^{\circ}$

05

$\left\{{ }^{\circ} \mathrm{O}^{\circ}\right.$

already

\{E1 nods slightly

$06\{(0.4)$

$\{$ E2 \& E3 nod continuously

$07 \mathrm{E} 2: \quad(j \circ 0)$

yeah

08 E4: O[n.

yes.

09 E?: [joo.

yeah.

10 L:-> et se on nyt teille tuttu et sielt

so you are now familiar with it so there

11 löytyy kans hyviä.

you can also find good things.

((2 lines omitted))

14 sielt- sitä kannattaa hyödyntää?

there- it is worth using?

$15 \quad($. 
16 L: en [tä,

and what about,

17 E5: [mis-mis- mistä \{se. (.) mi- missä se on niinku fro- fro- from where. (.) whe- where is it like

$\{L$ looks at the computer

$18\{$ lähinnä, (.) >et< (0.3) [mistä mä sen mainly (.) $>$ so< (0.3) where can I

$\{I$ sits by the computer and starts browsing

$19 \mathrm{~L}:$

[tota: ,

err

20 E5: h [aen.

get it.

21 L: [vastaustuki.

answer support.

22

$(0.8)$

23 L: mä tarkotan nyt sitte ihan sitä:, what I mean now is exactly tha:t,

$24 \quad(1.0)$

25 E6: siis Yritys X piste fiitä (--)

Organization $X$ (name of organization) dot fi right

26 L: Yritys X piste fiissä ni tota:,

in Organization $X$ dot $f i$ so er:,

27

$(2.1)$

28 E8: vastaus verkko vai.

do you mean answer net

llooks at $L$

((5 lines omitted))

34 L: tääl on tää vastausverkko mä tarkotin tätä

here it is this answer net I meant this

35

\{mä sanoin väärin vastaustuki, (0.2)

I said wrongly answer support (0.2)

\{looks to her side)

The lecturer's question (lines 3-5) deals with some written instructions. An interesting feature is that the lecturer does not use the correct name for the instructions, which is 
'Lavi's answer net'. Instead she uses the expression 'Lavi's answer support thing'. We will see later that this leads to a misunderstanding in the case of (at least) one new employee.

The knowledge-probing question in this extract deals with the kind of information the participants could have acquired during the orientation program and it prefers a positive response. However, the lecturer frames her question (lines 1-2) by stating explicitly that she is responsible for delivering the information to the audience if the participants do not already have it. In other words, she treats it as a possible alternative that the new employees do not yet have the knowledge in question.

The lecturer receives several affirmative responses in lines 5-9: five members of the audience react to the question either by nodding or presenting a type-conforming answer (on, joo). It is not surprising, then, that in the third turn of the sequence (line 10) the lecturer expresses a positive conclusion as regards the audience's knowledge of this. After her conclusion, the lecturer goes on to evaluate the instructions (lines 10-13, part of it now shown) and finally suggests that the participants should use them (line 14). Then, after a micropause, the lecturer seems to be initiating another question: entä-'and what about--'. At this moment, however, she is interrupted by one of the participants (E5) (lines 17, 18, 20), who reveals that she lacks the information the lecturer has previously asked about. She does this by asking where the written instructions are to be found on the organization's website.

E5's question changes the direction of the encounter: the lecturer revises her activities. In keeping with the norm that she should deliver information that the employees lack, and in line with the pedagogical aims of new employee orientation (cf. Hindmarsh et al. 2011), she works towards filling the knowledge gap. She does not, however, directly answer the question, but starts looking for the information on the organization's website in order to show it. While she is browsing, it turns out that the misleading term ('Lavi's answer support thing') may have caused the misunderstanding in the first place: not all the employees recognized that 'answer support thing' actually referred to 'answer net'.

The exceptional case in Extract 5 gives more evidence to support our claim that the lecturer's task is practical. He/she has no way of knowing what all the participants know. All he/she can do is draw a conclusion that is good enough for practical purposes, as this lecturer does in Extract 5. As the lecturer necessarily relies on inconclusive evidence, he/she can make a mistake and be corrected.

\section{Discussion}

In this paper, we have analyzed knowledge-probing question-answer sequences in new employee orientation lectures. We have concentrated on the third turn of the sequence, in which the lecturer reveals her or his conclusion as regards what the employees know. 
In particular, we have looked at the third turn from two perspectives: the resources the lecturer uses to reach a particular kind of conclusion, and the way she or he goes on after the conclusion.

The third turn by the lecturer is important in that it epitomizes what new employee orientation as an institutional encounter is all about. The essence of new employee orientation is to ensure that new employees possess sufficient knowledge to be able to begin working in the organization. Knowledge-probing question-answer sequences are a tool through which that ensuring is, in part, actualized. And, in the third turn, the lecturer displays her or his understanding that she or he is responsible for ascertaining that a sufficient level of knowledge has been reached. That is, not knowing is accountable, it is a situation that needs to be remedied.

The conclusion the lecturer reaches is, however, an unavoidably practical one. It is not based on a survey of all the new employees. Rather, it is always only a small minority of them who respond to the questions. The responses may be both verbal and nonverbal, and some of them are equivocal as to whether they actually constitute positive or negative answers. Additionally, it may be difficult for the lecturer to see or hear all the responses. Thus, what the lecturer does is reach a conclusion, based on inconclusive evidence, that is good enough for all practical purposes. The evidence consists mainly of the different responses of some of the employees, but the conclusion is also contingent on the expectations that are identifiable in the question. If the question displays the expectation that all or most of the employees are knowledgeable, a few positive responses, in the absence of clear negative ones, suffice to convince the lecturer. When, on the other hand, the expectation in the question is that only a few are going to be knowledgeable, a few positive responses do not lead to the conclusion that the employees know enough. The lecturer must make moment-by-moment, practical decisions on what the employees do or do not know and what the consequences will be for the flow of the ongoing lecture as well as for the whole orientation program.

The results of our study also make clear both the pros and the cons of group-based orientation lectures. While they are effective in that information can be delivered to a large group of people at the same time, they have the disadvantage that it is challenging for the organizers of the orientation program to follow the learning process of each individual: the learning process must be monitored on the group level, with individuals as representatives of the group. These kinds of challenges and ways of managing them may be relevant in different kinds of multi-party encounters with pedagogical objectives, for example, classroom interaction (Margutti 2006), group supervision at a university (Day \& Kjærbeck 2012) and educational programs (Lindwall \& Lymer 2011).

In a more general sense, our study sheds light on the organization of knowledge in question-answer sequences. In particular, we would like to highlight the role of the background activity of which the question-answer sequence is a part. On the one hand, the knowledge-probing question is clearly a 'real' question: the questioner is treated as less knowledgeable and those who answer are expected to know about their own 
experiences. On the other hand, it is equally crucial to see the question-answer sequence as part of the lecture as a whole, where the lecturer's task is to deliver relevant information to the employees during the limited time she or he has been allotted. With regard to that information and the sort of knowledge it relates to, it is the lecturer who is treated as more knowledgeable. Consequently, the purpose of the question is not just to find out what the employees know, but also to reach a decision as to what kind of information needs to be delivered after the question-answer sequence (for a similar observation in a peer learning context, see Kim, in press). In this interactional context, the state of the participants' knowledge becomes a practical issue, an issue that needs to be resolved there and then, in a way that makes it possible to proceed. This also means that the questioner needs to make an evaluation based on the answers. This task of evaluation is, however, different from the one following test questions: it is not the correctness of the answers that is evaluated but the extent of the answerers' knowledge vis-à-vis a desirable state of knowledge. Thus, we can see how question-answer sequences in institutional contexts are part of wider institutional activities with complex sets of epistemic rights and obligations, among which the participants must maneuver.

Finally, as there are no earlier studies of interaction in group-based new employee orientation, our study lays the foundation for understanding what orientation lectures are like as interactional encounters and what their role is and can or cannot be as part of the orientation process. At the same time, it opens up horizons for further study. We would like to stress the need for longitudinal interactional studies of the new employee orientation process, which usually includes both lectures and training. As part of such longitudinal studies, an intervention approach (see Antaki, 2011) would also be possible. For example, it would be possible to test different kinds of questions for probing the state of employees' knowledge. With more information about how learning comes about and how it is monitored during different stages of the learning process, we could reach a better understanding of how best to organize orientation programs to the advantage of both the organization and its new employees.

\section{References}

Antaki, C. (2011). Six kinds of applied conversation analysis. In: Antaki, C. (ed.), Applied Conversation Analysis: Intervention and Change in Institutional Talk. Palgrave Macmillan, London, pp. 1-14.

Artemeva, N. \& Fox, J., 2010. Awareness versus production: Probing students' antecedent genre knowledge. Journal of Business and Technical Communication 24 (4), 476-515.

Day, D. \& Kjærbeck, S., 2012. Treating student contributions as displays of understanding in group supervision. In: Rasmussen, G., Brouwer C. E. \& Day, D. (Eds.), Evaluating Cognitive Competences in Interaction. John Benjamins Publishing Company, Amsterdam, pp. 67-88. 
Goodwin, C., 1994. Professional vision. American Anthropologist 96 (3), 606-633.

Goodwin, C., 2000. Action and embodiment within situated human interaction. Journal of Pragmatics 32, 1489-1522.

Griffin, A., Colella, A. \& Goparaju, S., 2000. Newcomer and organizational socialization tactics: an interactionist perspective. Human Resource Management Review 10 (4), 453-474.

Heinemann, T., Steensig, J. \& Lindström, A., 2011. Addressing epistemic incongruence in question-answer sequences through the use of epistemic adverbs. In: Stivers, T, Mondada, L. \& Steensig, J. (Eds.), The Morality of Knowledge in Conversation. Cambridge University Press, Cambridge, pp. 107-130.

Heritage, J., 2012a. Epistemics in action: Action formation and territories of knowledge. Research on Language and Social Interaction 45 (1), 1-29.

Heritage, J., 2012b. The epistemic engine: Sequence organization and territories of knowledge. Research on Language and Social Interaction 45 (1), 30-52.

Heritage, J., 2013. Epistemics in conversation. In Sidnell, J. \& Stivers, T. (Eds), The Handbook of Conversation Analysis. Blackwell Publishing Ltd, West Sussex, pp. 370394.

Hindmarsh, J., Reynolds, P. \& Dunne, S., 2011. Exhibiting understanding: The body in apprenticeship. Journal of Pragmatics 43, 489-503.

Kim, Y., (in press). "'What is story-steruh type?': Knowledge asymmetry, intersubjectivity, and learning opportunities in conversation-for-learning. Applied Linguistics.

Klein, H. \& Weawer, N., 2000. The effectiveness of an organizational-level orientation training program in the socialization of new hires. Personnel Psychology 53, 47-66.

Koskela, I. \& Arminen, I., 2012. The embedded evaluations in air traffic control training. In: Rasmussen, G., Brouwer C. E. \& Day, D. (Eds.), Evaluating Cognitive Competences in Interaction. John Benjamins Publishing Company, Amsterdam, pp. 1542 .

Lindwall, O. \& Lymer, G., 2011. Uses of “understand” in science education. Journal or Pragmatics 43, 452-474.

Margutti, P., 2006. "Are you human beings?" Order and knowledge construction through questioning in primary classroom interaction. Linguistics and Education 17, 313-346.

Mehan, H., 1979. Learning Lessons. Social Organization in the Classroom. Harvard University Press, Cambridge.

Melander, H. \& Sahlström, F., 2009. Learning to fly - The progressive development of situation awareness. Scandinavian Journal of Education Research 53 (2), 151-166. 
Mondada, L., 2003. Working with video: how surgeons produce video records of their actions. Visual Studies 18 (1), 58-73.

Nissi, R. \& Lehtinen, E., 2016. Negotiation of expertise and multifunctionality: PowerPoint presentations as interactional activity types in workplace meetings. Language \& Communication 48, 1-17.

Raymond, G., 2010. Grammar and social relations. Alternative forms of yes/no-type initiating actions in health visitor interactions. In: Freed, A. F. \& Ehrlich, S. (Eds.), "Why do you ask?" The Function of questions in Institutional Discourse. Oxford University Press, Oxford, pp. 87-107.

Sacks, H., (1987). On the preferences for agreement and contiguity in sequences in conversation. In Graham Button \& John R.E. Lee (eds.), Talk and Social Organisation. Clevedon: Multilingual Matters, 54-69.

Stephens, K. \& Dailey, S., 2012. Situated organizational identification in newcomers: impacts of preentry organizational exposure. Management Communication Quarterly 26 (3), 404-422.

Streeck, J., Goodwin, C. \& LeBaron, C., 2011. Embodied interaction in the material world: an introduction. In: Streeck, J., Goodwin, C. \& LeBaron, C. (Eds.), Embodied Interaction. Language and Body in the Material World. Cambridge University Press, Cambridge, pp. 1-26.

Stivers, T., Mondada L. \& Steensig J., 2011. Knowledge, morality and affiliation in social interaction. In: Stivers, T., Mondada, L. \& Steensig J. (Eds.), The Morality of Knowledge in Conversation. Cambridge University Press, Cambridge, pp. 3-24.

Svennevig, J. (2010). Pre-empting reference problems in conversation. Language in Society, 39, 173-202.

Wallace, K., 2009. Creating an effective new employee orientation program. Library Leadership \& Management 23 (4), 168-176.

VISK = Hakulinen, A., Vilkuna, M., Korhonen, R., Koivisto, V., Heinonen, T. R. \& Alho, I., 2004. Iso suomen kielioppi. Suomalaisen Kirjallisuuden Seura, Helsinki. http://scripta.kotus.fi/visk 
FIGURES 1 AND 2

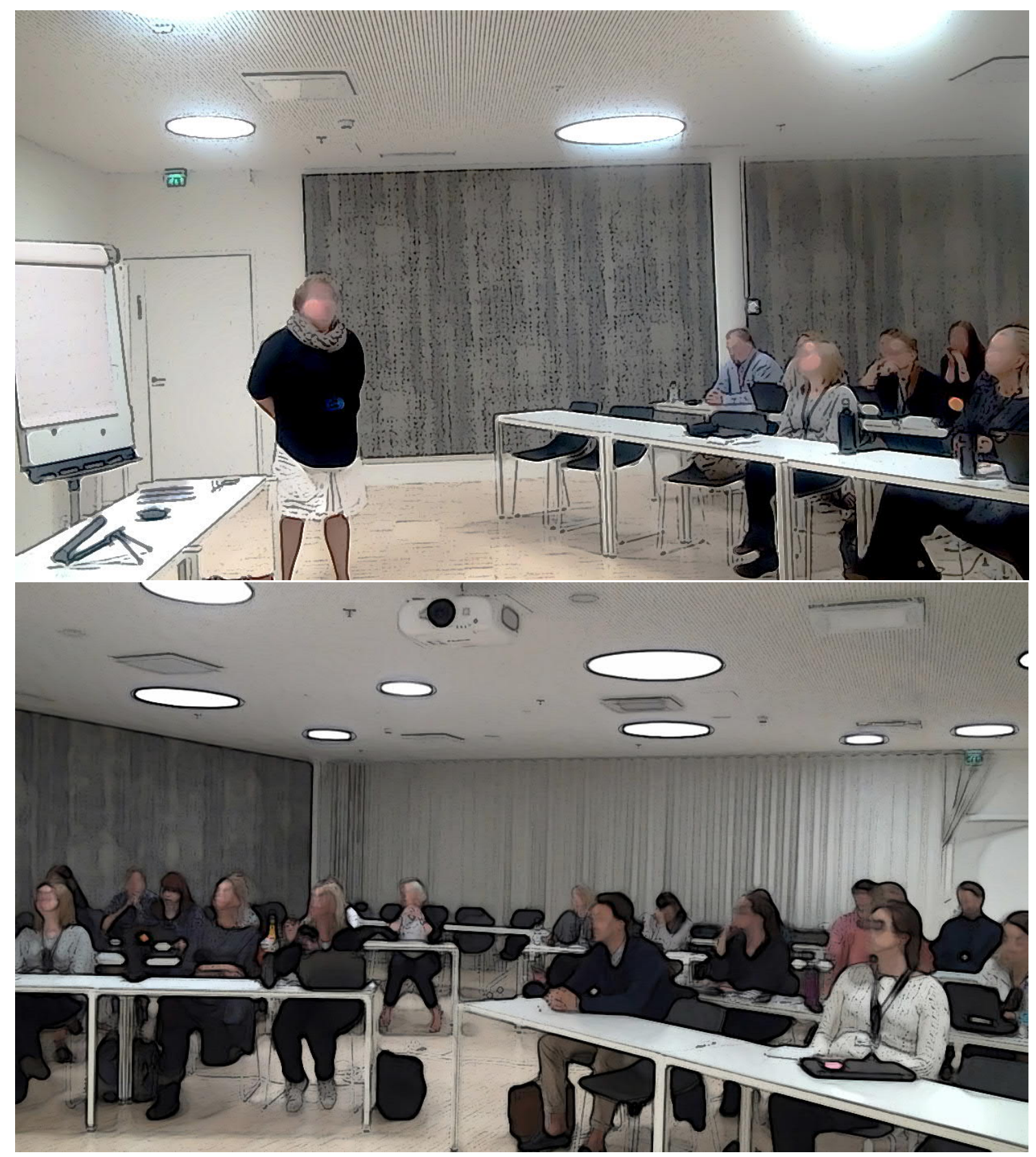

